BIS WORKING PAPERS

No. 60 - November 1998

\title{
OUTPUT GAP UNCERTAINTY: \\ DOES IT MATTER FOR THE TAYLOR RULE?
}

by

Frank Smets

BANK FOR INTERNATIONAL SETTLEMENTS

Monetary and Economic Department

Basle, Switzerland 
BIS Working Papers are written by members of the Monetary and Economic Department of the Bank for International Settlements, and from time to time by other economists, and are published by the Bank. The papers are on subjects of topical interest and are technical in character. The views expressed in them are those of their authors and not necessarily the views of the BIS.

Copies of publications are available from:

Bank for International Settlements

Information, Press \& Library Services

P.O. Box

CH-4002 Basle, Switzerland

Fax: $+4161 / 2809100$ and +4161/2808100

The present publication is also available on the BIS Web site (www.bis.org).

(C) Bank for International Settlements 1998.

All rights reserved. Brief excerpts may be reproduced or translated provided the source is stated. 


\title{
BIS WORKING PAPERS
}

No. 60 - November 1998

\section{OUTPUT GAP UNCERTAINTY: DOES IT MATTER FOR THE TAYLOR RULE?}

\author{
by \\ Frank Smets *
}

\begin{abstract}
This paper analyses the effect of measurement error in the output gap on efficient monetary policy rules in a simple estimated model of the US economy. While it is a well-known result that such additive uncertainty does not affect the optimal feedback rule in a linear-quadratic framework, it is shown that output gap uncertainty can have a significant effect on the efficient response coefficients in restricted instrument rules such as the popular Taylor rule. Output gap uncertainty reduces the response to the current estimated output gap relative to current inflation and may partly explain why the parameters in estimated Taylor rules are often much lower than suggested by optimal control exercises which assume the state of the economy is known.
\end{abstract}

* I thank Lucy Ellis, my discussant, and participants in the workshop on "Monetary policy-making under uncertainty", held at the Reserve Bank of New Zealand on 29-30th June 1998, for very useful comments. I am also indebted to Alison Spurway for proof-reading and Stephan Arthur for overseeing the publication. 



\section{Contents}

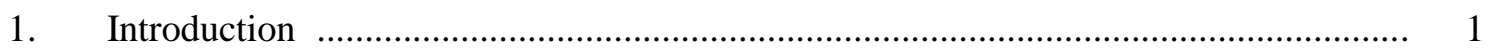

2. Output gap uncertainty in a simple model of the US economy

3. Efficient instrument rules when the state of the economy is known ........................... 7

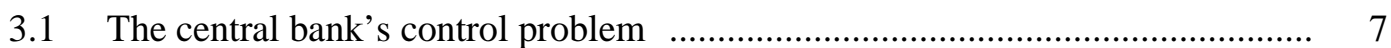

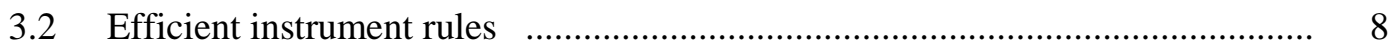

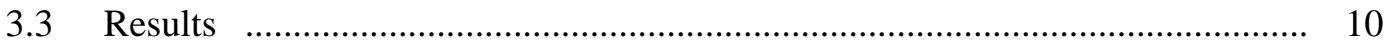

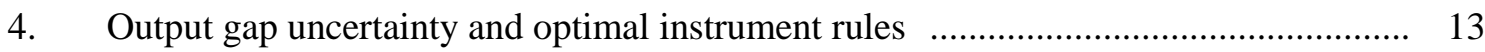

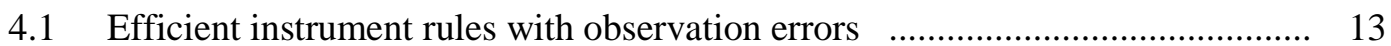

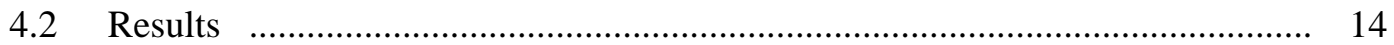

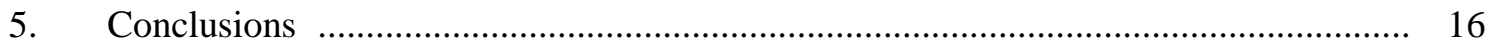

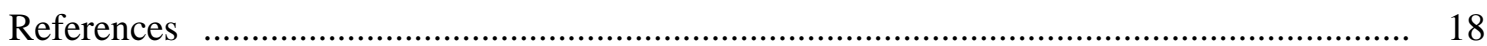





\section{Introduction}

This paper analyses the effect of uncertainty in the measurement of the output gap on monetary policy rules in a simple estimated linear model of the US economy. There are at least two reasons why this topic is of interest. First, following the work by Kuttner (1994) and Staiger, Stock and Watson (1996), there is increasing evidence that indicators of aggregate capacity utilisation such as the NAIRU or the output gap are measured with a considerable margin of uncertainty. ${ }^{1}$ However, there is little formal analysis of the effects of this uncertainty on monetary policy behaviour. ${ }^{2}$ Staiger et al. (1996) conjecture that "monetary policy in the presence of measurement error ... is consistent with placing less weight on poorly measured targets". More recently, however, Estrella and Mishkin (1998) conclude: "Uncertainty about the level of the NAIRU has no influence on the setting of policy instruments, although it does affect the value of the objective function. This type of uncertainty makes the policymaker worse off, but does not alter the policymakers' behaviour" (see also Wieland (1997)).

The results in this paper are consistent with both of the statements above. Because output gap uncertainty enters additively into the linear-quadratic framework of this paper, it does not affect the optimal linear instrument rule. Estrella and Mishkin (1998) base their conclusions on this wellknown certainty equivalence result. However, this result does not apply to restricted instrument rules such as the popular Taylor rule, which links the central bank's policy rate to only two variables, the current inflation rate and the output gap (Taylor (1993)). Below, I show that measurement error in the US output gap considerably reduces the optimal weight on the output gap in such restricted instrument rules. This provides evidence in favour of the conjecture of Staiger et al. (1996) mentioned above.

Second, while restricted instrument rules such as the Taylor rule have become increasingly popular as both a positive and a normative tool to analyse central bank behaviour, there has been less consensus on how large the feedback parameters should be on output and inflation. In his original contribution, John Taylor proposed a parameter of 1.5 on inflation and 0.5 on the output gap to explain recent Fed behaviour. Similarly, parameters in estimated Taylor-type reaction functions for a number of other countries are often close to these values. ${ }^{3}$ In contrast, many papers that calculate efficient Taylor rule parameters using model economies often come to the conclusion that the optimal feedback parameters should be much higher. For example, using a simple estimated model of the US economy Rudebusch and Svensson (1998) find that, while the Taylor rule does almost as well as the optimal feedback rule in minimising a loss function over output, inflation and interest rate variations, the optimal parameters are larger than two in most cases. Similarly, Levin (1996) compares the

1 Cross-country evidence can be found in Gerlach and Smets (1997) and Laubach (1997).

2 One exception which came to my attention after finishing the first draft of this paper is Rudebusch (1998), who addresses the same question using a somewhat different methodology and comes to very similar conclusions.

3 See, for example, Clarida, Gali and Gertler (1998). 
performance of the original Taylor rule with the Henderson-McKibbin rule, which has the same arguments as the Taylor rule but feedback parameters of two on both output and inflation. He finds that the latter rule performs better in stabilising output and inflation in the Fed's macro model. ${ }^{4}$ Finally, on the basis of a simple calibrated model, Ball (1997) argues that for a central bank that cares about variations in output and inflation an efficient feedback parameter on the output gap should be much larger than the one suggested by Taylor (1993).

There are various potential explanations for this discrepancy between actual central bank behaviour and the feedback these optimal control exercises suggest. One explanation may be that central banks have an interest rate smoothing objective which would tend to reduce the central bank's immediate response to current output and inflation developments. Another interpretation, following the original insight of Brainard (1969), is that uncertainty about the effects of policy on the economy makes the central banks behave more cautiously. ${ }^{5}$ In this paper, I focus on measurement error in the output gap as an explanation for the smaller observed response to the output gap. I show below that such measurement error can partially explain why central banks respond relatively more to inflation than to the output gap, compared with a situation in which the output gap is known.

The rest of the paper is structured as follows. In the next section, I estimate a simple model for the US economy that captures the way central banks think about the transmission process in a closed economy. The model is almost identical to that used by Rudebusch and Svensson (1997) (RS). However, in contrast to RS, I estimate the model and the output gap simultaneously using an unobservable components methodology and show that there is considerable uncertainty surrounding the estimate of the output gap.

In Section 3, I derive the optimal instrument rule for a quadratic loss function over variations in inflation, the output gap and interest rate changes under the assumption that the central bank observes the current output gap. Following RS, I compare the loss under the optimal feedback rule with the losses from restricted optimised feedback rules such as the Taylor rule.

In Section 4, I then perform a similar analysis in which measurement error in the estimated output gap is taken into account. This allows me to show how the optimal parameters in the feedback rules change with changes in output gap uncertainty. Finally, Section 5 briefly discusses the policy relevance of these results and contains some suggestions for future research.

4 See Henderson and McKibbin (1993). See also Brayton et al. (1998).

5 A number of recent papers, including Cecchetti (1998), Clarida et al. (1997), Estrella and Mishkin (1998), Sack (1998), Svensson (1997) and Wieland (1998), have recently picked up Brainard's theme in the context of the literature on monetary policy rules. See also Peersman and Smets (1998) and Rudebusch (1998). 


\section{Output gap uncertainty in a simple model of the US economy}

In this section, I estimate a simple empirical model for the US economy along the lines of RS. The main difference is that, while RS take a measure of the US output gap as given in the model estimation, I simultaneously estimate the model and the output gap using unobservable components techniques. This methodology extends the work by Kuttner (1994) and Gerlach and Smets (1997).

The estimated model has the following form:

$$
\begin{aligned}
& \pi_{t+1}=\alpha(L) \pi_{t}+\beta z_{t}+\varepsilon_{t+1}^{\pi} \\
& z_{t+1}=\varphi_{1} z_{t}+\varphi_{2} z_{t-1}+\lambda\left(i_{t}-\bar{\pi}_{t}\right)+\varepsilon_{t+1}^{z} \\
& y_{t+1}^{p}=\mu+y_{t}^{p}+\varepsilon_{t+1}^{y} \\
& y_{t}=y_{t}^{p}+z_{t}
\end{aligned}
$$

where $\pi_{t}$ is quarterly inflation in the GDP chain-weighted price index in percentage points at an annual rate; $\bar{\pi}_{t}$ is four-quarter inflation; $i_{t}$ is the quarterly average federal funds rate in percentage points at an annual rate; $y_{t}^{p}$ is the log of unobserved potential GDP in percentage points and $z_{t}$ is the unobserved output gap, i.e. the log difference between actual real GDP $\left(y_{t}\right)$ and potential GDP in percentage points.

The first equation can be interpreted as a Phillips curve which relates inflation to the lagged output gap and to lags in inflation. The second equation is the reduced form of an aggregate demand equation which relates the output gap to its own lags and to a lagged real interest rate, which is approximated by the difference between the nominal federal funds rate and average inflation over the previous four quarters. Note that in contrast to RS, who use an average annual interest rate, I use only the one-quarter lagged interest rate in the output gap equation. This simplifies the model somewhat as it reduces the number of state variables from nine to seven, without materially affecting the estimation results. ${ }^{6}$ Equation (3) assumes that potential output follows a random walk process with constant drift. Finally, equation (4) is an identity that defines the output gap.

In order to estimate model (1) to (4) using the Kalman filter and maximum likelihood methods, I write the model in state space form. The measurement equation is:

$$
\left[\begin{array}{c}
\Delta y_{t} \\
\pi_{t}
\end{array}\right]=\left[\begin{array}{cc}
1 & -1 \\
0 & \beta
\end{array}\right]\left[\begin{array}{c}
z_{t} \\
z_{t-1}
\end{array}\right]+\left[\begin{array}{c}
\mu \\
\alpha(L) \pi_{t-1}
\end{array}\right]+\left[\begin{array}{c}
\varepsilon_{t}^{y} \\
\varepsilon_{t}^{\pi}
\end{array}\right]
$$

6 Indeed, the value of the likelihood function is somewhat larger for the model with one lag as opposed to four lags. 
The corresponding state equation is:

$$
\left[\begin{array}{c}
z_{t+1} \\
z_{t}
\end{array}\right]=\left[\begin{array}{cc}
\varphi_{1} & \varphi_{2} \\
1 & 0
\end{array}\right]\left[\begin{array}{c}
z_{t} \\
z_{t-1}
\end{array}\right]+\left[\begin{array}{c}
\lambda\left(i_{t-1}-\bar{\pi}_{t-1}\right) \\
0
\end{array}\right]+\left[\begin{array}{c}
\varepsilon_{t}^{z} \\
0
\end{array}\right]
$$

Assuming that each of the three shocks is independently normally distributed with variance-covariance matrix

$$
\Sigma_{\varepsilon}=\left[\begin{array}{ccc}
\sigma_{y}^{2} & 0 & 0 \\
0 & \sigma_{z}^{2} & 0 \\
0 & 0 & \sigma_{\pi}^{2}
\end{array}\right]
$$

one can form the likelihood function of the model (5) to (7) using the Kalman filter and derive the estimates of the model using maximum likelihood estimation. ${ }^{7}$

Table 1 reports the estimation results with quarterly data over the full sample period (1962:1-1997:4) and a sub-sample (1980:1-1997:4). As can be seen, all the important parameters have the expected sign and are significant. It is useful to compare these estimates with the ones in RS. I estimate the slope of the Phillips curve ( $\beta=0.21$ ) to be somewhat larger than $\mathrm{RS}$ ( $\beta=0.14$ ), while the effect of the real rate on the output gap is slightly smaller in absolute value $(\lambda=-0.06$ instead of $-0.10)$.

More importantly, the estimated autoregressive parameters in the output gap equation are much larger in absolute value and the output gap seems to be more persistent than in RS, while the persistence in the inflation equation is estimated to be smaller. The first autoregressive parameter in the inflation equation falls from 0.70 in the RS case to 0.38 in this model. While RS cannot reject the hypothesis that the sum of the autoregressive parameters in the inflation equation is one, this hypothesis is rejected at conventional significance levels in this model. Allowing for the simultaneous estimation of the output gap and the parameters of the model has the implication that the estimated output gap picks up some of the persistence in the inflation process. This relative difference in inflation and output gap persistence will have implications for the optimal feedback parameters that are calculated in the next section. ${ }^{8}$ Graph 1 summarises the transmission process of monetary policy in this model. It plots the effects of a 1 percentage point increase in the real interest rate during eight quarters on output and inflation.

7 Note that all variables including the growth rate of GDP, are de-meaned before the analysis. In addition, for the estimation over the shorter sample (Table 1), inflation is also detrended using a linear time trend.

8 The fact that a unit root in the inflation equation can be rejected does not imply that there is a long-run trade-off between output and inflation. It may just mean that during the sample the agents in the economy put a positive weight on the constant inflation target in forming their inflation expectations. As all of the policy rules considered in this paper assume the central bank targets the same constant inflation target (which equals the average inflation rate), this does not pose any additional problem in terms of the Lucas critique. 
Table 1

\section{Estimation results}

\begin{tabular}{|c|c|c|c|c|c|c|}
\hline & \multicolumn{3}{|c|}{ 1962:1 - 1997:4 } & \multicolumn{3}{|c|}{ 1980:1 - 1997:4 } \\
\hline$\varphi_{1}$ & 1.75 & $(0.08)$ & [22.44] & 1.74 & $(0.08)$ & [21.80] \\
\hline$\varphi_{2}$ & -0.81 & $(0.08)$ & [10.31] & -0.81 & $(0.07)$ & [11.33] \\
\hline$\beta$ & 0.21 & $(0.06)$ & [3.37] & 0.23 & $(0.08)$ & [2.90] \\
\hline$\lambda$ & -0.06 & $(0.02)$ & [3.26] & -0.07 & $(0.02)$ & {$[2.70]$} \\
\hline$\alpha_{1}$ & 0.38 & $(0.08)$ & {$[5.01]$} & 0.20 & $(0.11)$ & {$[1.50]$} \\
\hline$\alpha_{2}$ & 0.11 & $(0.08)$ & [1.42] & 0.03 & $(0.10)$ & {$[0.35]$} \\
\hline$\alpha_{3}$ & 0.23 & $(0.08)$ & {$[3.08]$} & 0.33 & $(0.10)$ & [3.19] \\
\hline$\alpha_{4}$ & 0.10 & $(0.06)$ & [1.57] & 0.04 & $(0.10)$ & {$[0.40]$} \\
\hline$\sigma_{y}^{2}$ & 0.54 & $(0.08)$ & {$[6.24]$} & 0.22 & & \\
\hline$\sigma_{z}^{2}$ & 0.05 & $(0.04)$ & {$[1.22]$} & 0.04 & & \\
\hline$\sigma_{\pi}^{2}$ & 1.17 & $(0.08)$ & [14.32] & 0.41 & & \\
\hline \multirow[t]{2}{*}{ Likelihood } & 249.45 & & & 60.74 & & \\
\hline & \multicolumn{3}{|c|}{$\alpha(1)=0.82, \varphi(1)=0.94$} & \multicolumn{3}{|c|}{$\alpha(1)=0.60, \varphi(1)=0.93$} \\
\hline
\end{tabular}

The right panel of Table 1, which gives the estimation results for the sub-sample 1980:11997:4, illustrates the stability of the full-sample estimation results. Many of the sub-sample parameters, including the slope of the Phillips curve and the sensitivity of the output gap to the real interest rate, are very similar to the full-sample estimates. One difference between the two samples is the reduced persistence of inflation in the post-1980 period.

Turning to the estimates of the variance-covariance matrix of the shocks, I find that the standard deviation of the inflation shocks is very similar to the one in RS, while the standard deviation of the output gap shocks is much smaller. Most importantly, however, I can easily reject the hypothesis that potential output follows a deterministic path around a constant trend, as can be seen from the estimate of the variance of the shocks to potential. In fact, the difference in likelihood with a model in which this variance is imposed to be zero is more than 4 , which is much larger than the usual standard chi-squared test with one degree of freedom would allow. Following Harvey (1988), Clark (1989) and Gerlach and Smets (1997), I allowed for a time-varying growth rate in the potential output equation in one of the alternative models I estimated (not reported). Consistent with the finding in Gerlach and Smets (1997), I could not reject the model with a constant potential growth rate. 
Graph 1

\section{The effects of a 1 percentage point interest rate rise}

Horizon: eight quarters, estimation period 1962:1-1997:4

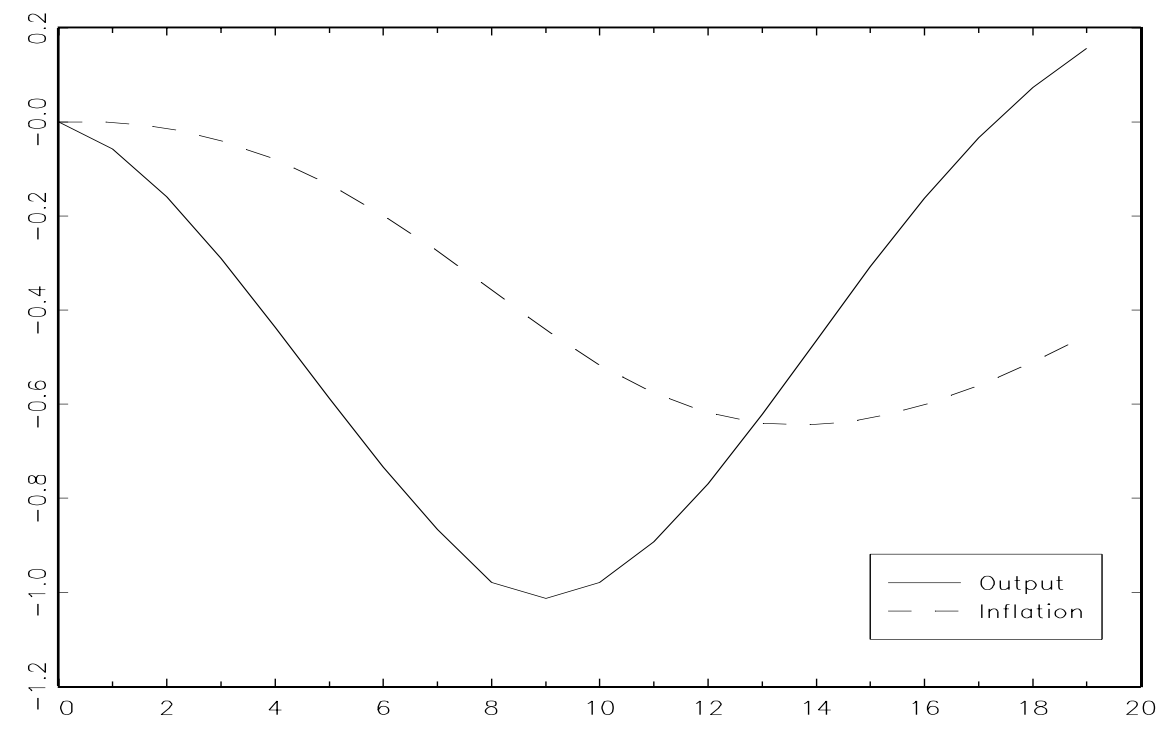

Graph 2 plots the one-sided and two-sided estimates of the output gap together with a two-standard-deviation confidence band. Consistent with the findings of Staiger et al. (1996) and Gerlach and Smets (1997), the uncertainty surrounding the estimates of the output gap is considerable. Typically, the standard deviation of the output gap is slightly larger than $1 \%$, suggesting that the estimated output gap needs to be at least $2 \%$ to be able to reject the hypothesis that it is significantly different from zero.

One striking difference with more conventional estimates of the output gap is the different level of the output gap before and after the great disinflation in the early 1980s. This is in particular striking in the one-sided estimates of the output gap (left panel). The main reason for this apparent persistence in the output gap is the behaviour of inflation and the real interest rate over the sample period. Because the real interest rate is estimated to have a significant negative impact on the output gap, the low and even negative real rates during the 1970s are associated with positive output gaps. Similarly, because of the positive association between output gaps and inflation, high and rising inflation is reflected in a positive output gap. The subsequent policy tightening following the appointment of Paul Volcker as Chairman of the Federal Reserve Board let to a dramatic fall in the output gap and the persistently high real rates during most of the 1980s and falling inflation are reflected in a persistently negative output gap in that period. 
Graph 2

\section{Estimated US output gap}

Estimation period: 1962:1-1997:4; two-standard-error confidence band
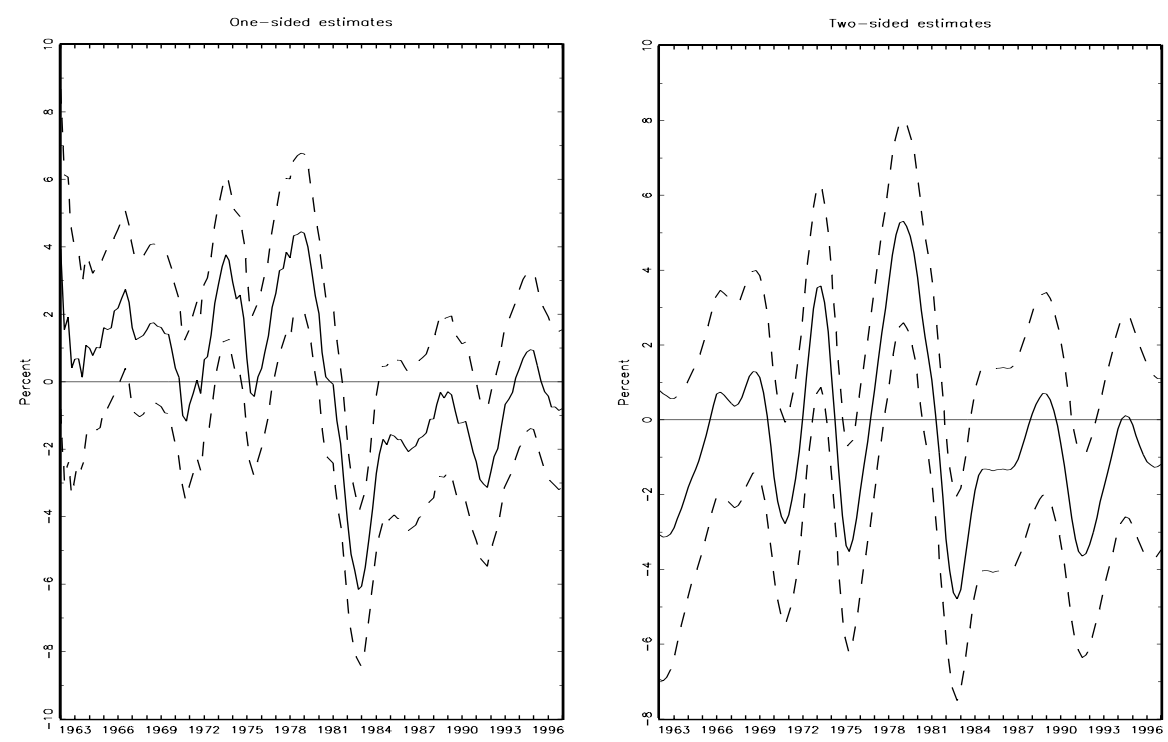

Before analysing the effects of the estimated output gap uncertainty on monetary policy, in the next section I describe the loss function of the central bank and derive efficient policy rules under the assumption that the output gap and the model of the economy are known with certainty.

\section{Efficient instrument rules when the state of the economy is known}

\subsection{The central bank's control problem}

In order to calculate the efficient policy rules in the estimated empirical model of the previous section, we consider the following loss function, ${ }^{9}$

$$
E\left(L_{t}\right)=\gamma \operatorname{Var}\left(\bar{\pi}_{t}\right)+(1-\gamma) \operatorname{Var}\left(z_{t}\right)+v \operatorname{Var}\left(i_{t}-i_{t-1}\right)
$$

The central bank cares about variability in the deviations of annual inflation from a constant inflation target, variations in the output gap and changes in the short-term interest rate. As all variables are demeaned before the analysis, equation (8) implies that the inflation target equals the mean inflation rate over the sample. In this section, I assume that the central bank observes not only current and past

9 This section follows the analysis in RS. They show how the loss function (8) is equivalent to a more standard intertemporal loss function with a discount rate equal to one. 
inflation and interest rates, but also the current and past output gap. In the next section, I will explicitly allow for measurement error in the output gap.

The central bank's task is to set its policy instrument, $i_{t}$, so as to minimise the loss function (8) subject to the dynamics of the economy as described by equations (1) and (2). The statespace representation of the economy is given by ${ }^{10}$

$$
X_{t+1}=A X_{t}+B i_{t}+v_{t}
$$

where the vector $X_{t}$ of state variables, the matrix $A$, the column vector $B$ and the disturbance vector $v_{t}$ are given by

$$
X_{t}=\left[\begin{array}{c}
z_{t} \\
\pi_{t} \\
z_{t-1} \\
\pi_{t-1} \\
\pi_{t-2} \\
\pi_{t-3} \\
i_{t-1}
\end{array}\right], \quad A=\left[\begin{array}{ccccccc}
\varphi_{1} & -\lambda / 4 & \varphi_{2} & -\lambda / 4 & -\lambda / 4 & -\lambda / 4 & 0 \\
\beta & \alpha_{1} & 0 & \alpha_{21} & \alpha_{3} & \alpha_{4} & 0 \\
1 & 0 & 0 & 0 & 0 & 0 & 0 \\
0 & 1 & 0 & 0 & 0 & 0 & 0 \\
0 & 0 & 0 & 1 & 0 & 0 & 0 \\
0 & 0 & 0 & 0 & 1 & 0 & 0 \\
0 & 0 & 0 & 0 & 0 & 0 & 0
\end{array}\right], \quad B=\left[\begin{array}{c}
\lambda \\
0 \\
0 \\
0 \\
0 \\
0 \\
1
\end{array}\right], \quad v_{t}=\left[\begin{array}{c}
\varepsilon_{t}^{z} \\
\varepsilon_{t}^{\pi} \\
0 \\
0 \\
0 \\
0 \\
0
\end{array}\right]
$$

The vector $Y_{t}$ of goal variables fulfils

$$
Y_{t}=C_{X} X_{t}+C_{i} i_{t}
$$

where $\quad Y_{t}=\left[\begin{array}{c}\bar{\pi}_{t} \\ z_{t} \\ i_{t}-i_{t-1}\end{array}\right], \quad C_{X}=\left[\begin{array}{ccccccc}0 & 1 / 4 & 0 & 1 / 4 & 1 / 4 & 1 / 4 & 0 \\ 1 & 0 & 0 & 0 & 0 & 0 & 0 \\ 0 & 0 & 0 & 0 & 0 & 0 & -1\end{array}\right], \quad C_{i}=\left[\begin{array}{l}0 \\ 0 \\ 1\end{array}\right]$

The loss function can then be written as

$$
E\left(L_{t}\right)=E\left(Y_{t}^{\prime} K Y_{t}\right)
$$

where $K$ is a $3 \times 3$ diagonal matrix with $(\gamma, 1-\gamma, \nu)$ on the diagonal.

\subsection{Efficient instrument rules}

In this paper I consider seven instrument rules. The benchmark rule is the unrestricted optimal linear feedback rule $(\mathrm{O})$, which is given by

$$
i_{t}=-\left(R+B^{\prime} V B\right)^{-1}\left(U^{\prime}+B^{\prime} V A\right) X_{t}=f X_{t}
$$

10 In order to allow for interest rate smoothing, the state-space representation also includes the lagged interest rate as a state variable. 
where the matrix $V$ satisfies the following equation

$$
V=Q+f^{\prime} R f+2 f^{\prime} U^{\prime}+\delta(A+B f)^{\prime} V(A+B f)
$$

and where $Q=C_{X}{ }^{\prime} K C_{X}, U=C_{X}{ }^{\prime} K C_{i}, R=C_{i}{ }^{\prime} K C_{i}$ and $\Sigma_{v}$ is the covariance matrix of the disturbance vector $v_{t}{ }^{11}$

Equation (12) illustrates the well-known result that in a linear-quadratic framework the optimal feedback rule is linear in the vector of state variables and the feedback parameters can be calculated from (12) by iterating on the Ricatti equation (13). The resulting minimised value of the loss function is given by

$$
\Psi=\operatorname{trace}\left(V \Sigma_{v}\right)
$$

In addition to the optimal linear feedback rule, I also consider six restricted instrument rules. The first four of these are all variants of the popular Taylor rule. The first restricted rule is the simple Taylor rule (T), and constrains the feedback of the policy rate to the current annual inflation rate and the current output gap,

$$
i_{t}=g_{\pi} \bar{\pi}_{t}+g_{z} z_{t}
$$

The second restricted rule is a forward-looking Taylor rule (FT). In such a rule, the central bank responds to an inflation forecast rather than to current inflation. Following RS, we assume the central bank responds to a constant-interest-rate inflation forecast, i.e. the inflation forecast is calculated under the assumption of a constant interest rate. The forecast horizon is assumed to be eight quarters.

$$
i_{t}=g_{\pi} \bar{\pi}_{t}^{e}+g_{z} z_{t}
$$

The third and fourth restricted rules (TS) and (FTS) correspond to the previous two rules, but allow for interest rate smoothing by including the lagged interest rate in the feedback list, i.e.

$$
i_{t}=g_{\pi} \bar{\pi}_{t}+g_{z} z_{t}+g_{i} i_{t-1}
$$

$$
i_{t}=g_{\pi} \bar{\pi}_{t}^{e}+g_{z} z_{t}+g_{i} i_{t-1}
$$

Finally, the last two restricted rules (F) and (FS) are pure inflation forecast rules with and without smoothing, i.e.

$$
i_{t}=g_{\pi} \bar{\pi}_{t}^{e}
$$

11 As shown in RS, minimising equation (8) subject to equation (9) is a standard stochastic linear regulator problem, which can be solved by using Bellman's equation of dynamic programming. See also Chow (1970) or Sargent (1987). 


$$
i_{t}=g_{\pi} \bar{\pi}_{t}^{e}+g_{i} i_{t-1}
$$

As each of the restricted rules can be written as a linear function of the vector of state variables (say $i_{t}=g X_{t}$ ), the dynamics of the model and the goal variables for a specific rule are given by 12

$$
X_{t+1}=M X_{t}+v_{t+1}
$$$$
Y_{t}=C X_{t}
$$

where $M=A+B g$ and $C=C_{X}+C_{i} g$.

The efficient feedback coefficients in each of the restricted instrument rules can then be calculated by minimising the loss function (8), which is given by

$$
E\left[L_{t}\right]=E\left[Y^{\prime}{ }_{t} K Y_{t}\right]=\operatorname{trace}\left(K \Sigma_{Y}\right)
$$

where $\Sigma_{Y}$ is the unconditional covariance matrix of the goal variables and is given by

$$
\Sigma_{Y}=C \Sigma_{X} C^{\prime}
$$

and $\Sigma_{X}$ is the covariance matrix of the state variables and is, in turn, related to the covariance matrix of the disturbances by the following equation

$$
\operatorname{vec}\left(\Sigma_{X}\right)=[I-(M \otimes M)]^{-1} \operatorname{vec}\left(\Sigma_{v}\right)
$$

\subsection{Results}

The upper panel of Table 2 gives the efficient feedback parameters for each of the seven instrument rules, the corresponding standard deviations of the goal variables, the value of the loss function and the ranking among the seven rules considered. Following RS, I assume for the base case that the central bank places equal weight on inflation and output deviations $(\gamma=0.5)$ and a weight of $v=0.25$ on the interest rate smoothing component.

The optimal feedback rule is given by

$$
i_{t}=0.35 \pi_{t}+0.22 \pi_{t-1}+0.17 \pi_{t-2}+0.07 \pi_{t-3}+2.97 z_{t}-2.23 z_{t-1}+0.50 i_{t-1}
$$

Comparing this optimal feedback rule with the one derived in RS, it is obvious that in this case the central bank leans much more against the output gap than against inflation. With a weight of 0.25 on the interest rate smoothing component, the parameter on the lagged interest rate is about one-half and very similar to the one derived by RS. 
Table 2

Results on volatility and loss $(\gamma=0.5, v=0.25)$

Estimation period: 1962:1-1997:4

\begin{tabular}{|l|c|c|c|c|c|}
\hline Rule & $\sigma_{\bar{\pi}_{t}}$ & $\sigma_{z_{t}}$ & $\sigma_{i_{t}-i_{t-1}}$ & Loss & Rank \\
\hline \multicolumn{5}{|c|}{ Without output gap uncertainty } \\
\hline Optimal & 1.28 & 0.85 & 0.98 & 1.42 & 1 \\
T $\left(g_{\pi}=1.34, g_{z}=2.06\right)$ & 1.33 & 0.96 & 0.98 & 1.59 & 3 \\
F $\left(g_{\pi}=1.58\right)$ & 1.58 & 1.60 & 0.58 & 2.63 & 7 \\
FT $\left(g_{\pi}=1.63, g_{z}=1.98\right)$ & 1.34 & 0.96 & 1.01 & 1.63 & 5 \\
TS $\left(g_{\pi}=1.64, g_{z}=2.59, g_{i}=-0.24\right)$ & 1.33 & 0.90 & 1.04 & 1.56 & 2 \\
FS $\left(g_{\pi}=1.83, g_{i}=-0.16\right)$ & 1.57 & 1.59 & 0.65 & 2.62 & 6 \\
FTS $\left(g_{\pi}=1.87, g_{z}=2.38, g_{i}=-0.18\right)$ & 1.35 & 0.91 & 1.07 & 1.61 & 4 \\
\hline \multicolumn{4}{|c|}{ With output gap uncertainty } & & \\
\hline Optimal & 1.44 & 1.37 & 0.84 & 2.15 & 1 \\
T $\left(g_{\pi}=1.17, g_{z}=1.45\right)$ & 1.47 & 1.42 & 0.87 & 2.29 & 3 \\
F $\left(g_{\pi}=1.58\right)$ & 1.58 & 1.60 & 0.58 & 2.63 & 7 \\
FT $\left(g_{\pi}=1.51, g_{z}=1.24\right)$ & 1.48 & 1.42 & 0.91 & 2.32 & 5 \\
TS $\left(g_{\pi}=1.13, g_{z}=1.42, g_{i}=0.03\right)$ & 1.47 & 1.42 & 0.86 & 2.28 & 2 \\
FS $\left(g_{\pi}=1.83, g_{i}=-0.16\right)$ & 1.57 & 1.59 & 0.65 & 2.62 & 6 \\
FTS $\left(g_{\pi}=1.37, g_{z}=1.18, g_{i}=0.08\right)$ & 1.48 & 1.43 & 0.88 & 2.31 & 4 \\
\hline
\end{tabular}

The greater importance of the output gap is also obvious in the restricted instrument rules. In contrast to RS, I find that the coefficient on the output gap in the simple Taylor rule is much larger than the coefficient on inflation. While the coefficient on inflation is relatively close to the one proposed by Taylor (1993), the coefficient on the output gap is much larger than the 0.5 he proposed. This result is consistent with the findings of Ball (1997). One reason for the relative importance of output versus inflation in the efficient Taylor rule is the greater relative degree of persistence in the output gap. Indeed, increasing the persistence in the inflation equation leads to a rise in the efficient feedback coefficient on inflation. Similarly, reducing the persistence of output leads to a fall in the efficient coefficient on the output gap. One implication of this finding is that, in an economy where inflation is well anchored because of the credibility of the central bank's inflation target, the central bank will have to lean relatively less against inflation and more against output.

12 See RS for a discussion of how the constant-interest-rate forecast can be calculated. 
Obviously, the efficient feedback coefficients in the Taylor rule will also depend on the weights in the objective function. Graph 3 plots the coefficients as a function of the weights on output relative to inflation and the weight on the interest rate smoothing component in the loss function. In this graph the symbol $\mathrm{O}$ to the left of the solid curves stands for strict output targeting, i.e. $\gamma=0$, while the symbol I to the right stands for strict inflation targeting, i.e. $\gamma=1$. The middle curve corresponds to a weight on interest rate smoothing, $v$, equal to 0.25 as in the base case. The upper and lower curves correspond to, respectively, a lower and a higher weight on interest rate smoothing in the loss function.

\section{Graph 3}

\section{Efficient Taylor rule parameters}

Estimation period: 1962:1-1997:4

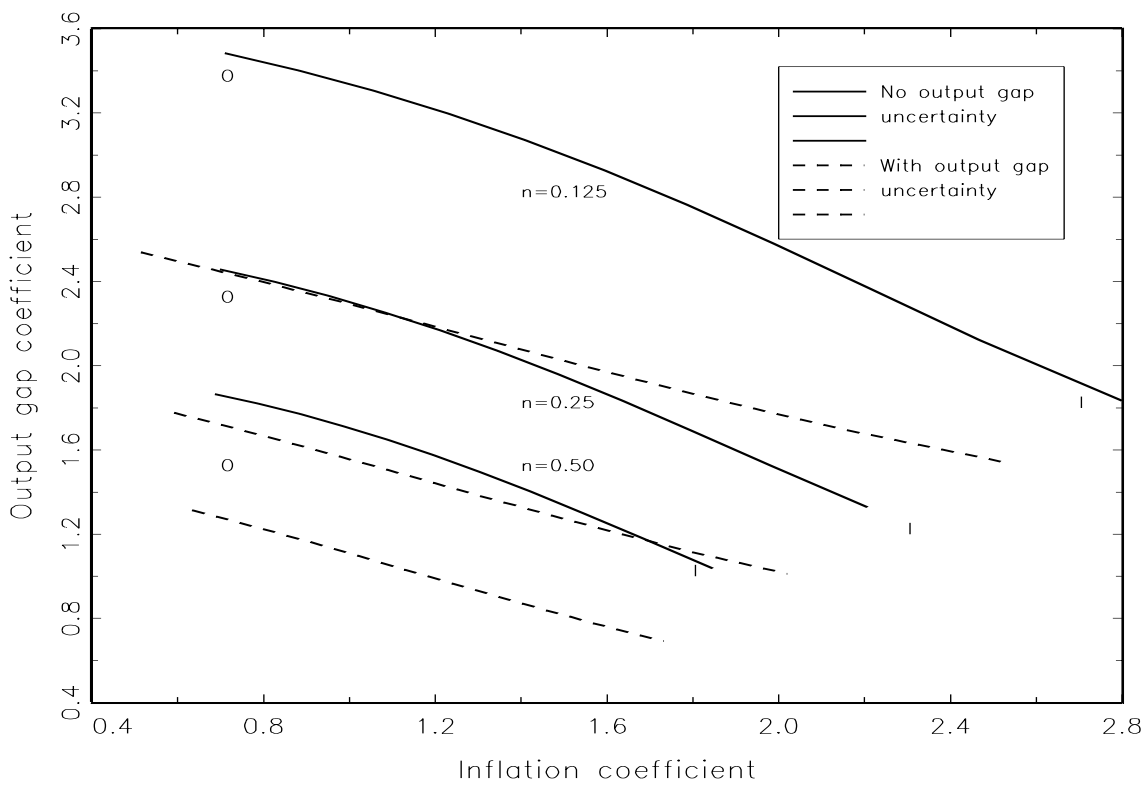

A couple of observations are worth making. First, for a given weight on interest rate smoothing, it appears that the optimal feedback coefficient on the output gap falls and the one on inflation rises as the relative weight on output is reduced. However, even if the central bank only cares about inflation stabilisation, i.e. $\gamma=1$, it will respond significantly to the output gap. Of course, this reflects the crucial role of the output gap in attempts at inflation stabilisation in this model. The weight on interest rate smoothing does affect the response to output and inflation significantly. As interest rate smoothing becomes more important, both coefficients fall quite considerably. 
In terms of the relative ranking of the six instrument rules, the results in Table 2 are very similar to the ones reported by RS. The simple Taylor rule with and without interest rate smoothing performs as well as the forward-looking rules. Moreover, the loss under the simple Taylor rule is relatively close to the loss under the optimal feedback rule. The implication appears to be that in this particular economy not much is lost by restricting the optimal feedback rule to the simple Taylor rule. This is not too surprising as the model is very simple. In such a situation, inflation and the output gap may be close to sufficient statistics of the state of the economy.

\section{Output gap uncertainty and optimal instrument rules}

In this section, I analyse the effect of measurement error in the output gap on the efficient instrument rules considered in Section 3. Equation (9) of Section 3.1 still governs the dynamics of the economy, but now I more realistically assume that two of the state variables, $z_{t}$ and $z_{t-1}$, are unobserved. Current and past growth rates of real GDP, $\Delta y_{t}$, are observed, but could be due to either a change in the growth of potential output or a change in the output gap, so that the central bank faces a signal extraction problem.

In matrix notation, the observation equation equivalent to equation (9) is given by

$$
W_{t}=D X_{t}+\eta_{t}
$$

where the vector of observables $W_{t}$, the matrix $D$ and the vector $\eta_{t}$ are given by

$$
W_{t}=\left[\begin{array}{c}
\Delta y_{t} \\
\pi_{t} \\
i_{t-1}
\end{array}\right], \quad D=\left[\begin{array}{ccccccc}
1 & 0 & -1 & 0 & 0 & 0 & 0 \\
0 & 1 & 0 & 0 & 0 & 0 & 0 \\
0 & 0 & 0 & 0 & 0 & 0 & 1
\end{array}\right], \quad \eta_{t}=\left[\begin{array}{c}
\varepsilon_{t}^{y} \\
0 \\
0
\end{array}\right]
$$

The central bank's estimate of the current state of the economy is then given by $E_{t} X_{t}=E\left[X_{t} \mid W_{t}\right]$.

\subsection{Efficient instrument rules with observation errors}

When the state of the economy is imperfectly observed, the optimal linear feedback rule is given by

$$
i_{t}=-\left(R+B^{\prime} V B\right)^{-1} \text { ' }\left(U^{\prime}+B^{\prime} V A\right) E_{t}\left(X_{t}\right)=f E_{t}\left(X_{t}\right)
$$

where $V$ is again determined by equation (13). Comparing equations (22) and (12), it is clear that measurement errors in the state variables do not affect the optimal feedback parameters. The only difference between (12) and (22) is that in the latter case the feedback is on the estimated state 
variables rather than on the actual state variables. ${ }^{13}$ In fact, the Kalman filter applied in Section 2 gives the optimal estimate of the state variables given the structure of the economy and the vector of observables.

While the optimal feedback parameters are not affected, the loss function will be as measurement error will increase the variability of the goal variables. Under the optimal feedback rule (22), the loss is given by

$$
\Psi^{*}=\operatorname{trace}\left(V \Sigma_{v v}\right)+\operatorname{trace}\left(\left(f^{\prime} R f+2 f^{\prime} U^{\prime}+f^{\prime} B^{\prime} V B f\right) \Sigma_{s}\right)
$$

where $\Sigma_{S}$ is the covariance matrix of the observation errors given by the Kalman filter of Section 2 .

The efficient feedback parameters in the restricted instrument rules are again calculated by minimising the unconditional loss in equation (17). However, with measurement error in the output gap, the covariance matrices of the goal variables and the state variables, respectively, are now given by

$$
\begin{aligned}
& \Sigma_{Y}=C \Sigma_{X} C^{\prime}+C_{X} \Sigma_{S} C_{X}, \text { and } \\
& \left.\operatorname{vec}\left(\Sigma_{X}\right)=[I-(M \otimes M)]^{-1}\left[\operatorname{vec}\left(\Sigma_{v}\right)+[(A \otimes A)-I)\right] \operatorname{vec}\left(\Sigma_{S}\right)\right]
\end{aligned}
$$

\subsection{Results}

The lower panel of Table 2 presents the results of the optimal control exercises when the estimated uncertainty in the measurement of the output gap is taken into account. As already shown, the optimal feedback parameters are not affected. However, the standard deviation of all goal variables, and thus the loss function, has increased. Although both inflation and interest rates are observed, their standard deviations increase because they are affected by the response of the central bank to the noisy output gap.

More interesting are the results concerning the restricted feedback rules. Comparing the two panels of Table 2, it is obvious that the feedback parameter on the output gap is significantly reduced (from 2.06 to 1.45 for the Taylor rule). Somewhat more surprisingly, the feedback parameter on inflation is also reduced, although much less so.

The relative ranking of the different rules is not affected. However, because the pure forecasting rule is not affected very much by the measurement error in the output gap, its relative position improves compared with the other rules.

13 See Chow (1970) for a derivation of the optimal linear feedback rule with measurement error in the state variables. This result is sometimes called a separation theorem. 
Graph 4 plots the efficient Taylor rule parameters as a function of output gap uncertainty. As the standard deviation of the output gap increases, the response to the output gap falls at an increasing rate. The efficient response coefficient is still relatively high (about 1.4) at the estimated standard deviation (around 1.1\%). However, further increasing the standard deviation results in a rapid drop in the feedback parameter. A standard deviation of about 1.5 would, in this model, be consistent with a parameter of 0.5 on output, as suggested by Taylor (1993). When the standard deviation is larger than $1.6 \%$, it becomes optimal not to respond to the output gap.

Graph 4

Taylor rule coefficients as function of output gap uncertainty

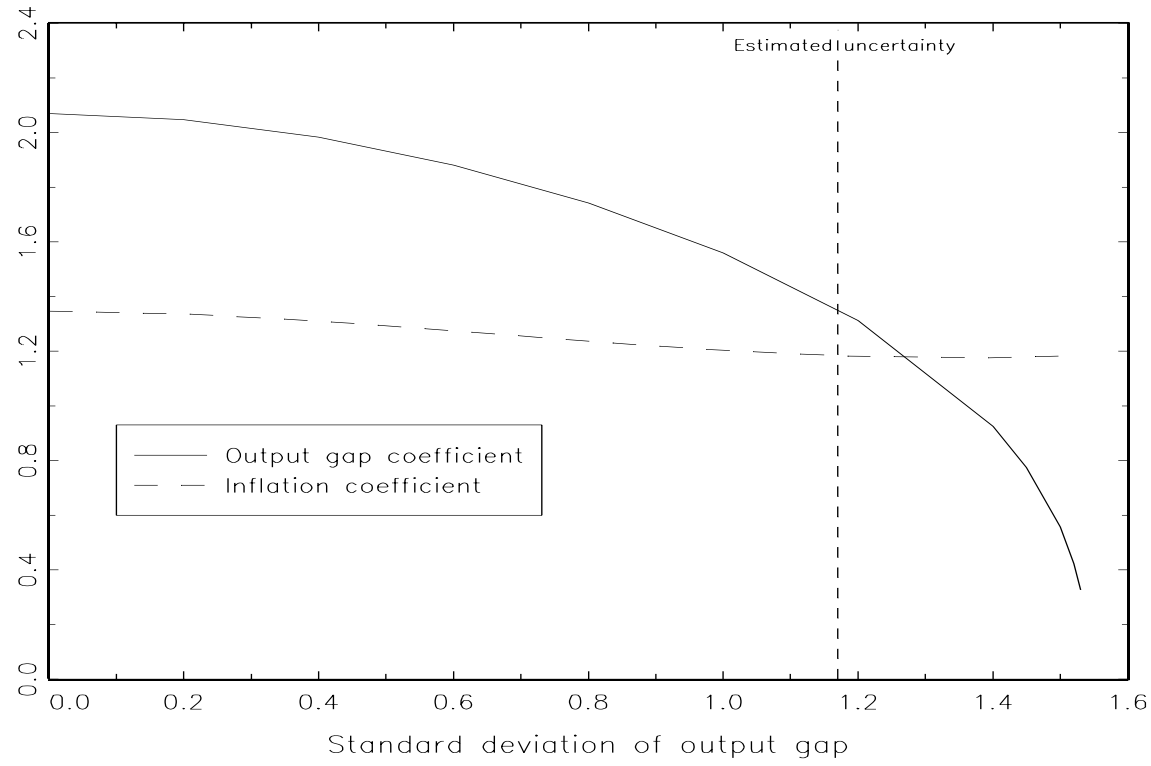

Graph 3 shows that the negative effect of higher output gap uncertainty on the Taylor rule parameters is robust to various weights in the objective function. The dashed lines represent the efficient Taylor rule parameters when the estimated output gap uncertainty is taken into account. In all cases the efficient Taylor rule parameters fall, but by how much depends on the weights in the objective function. Obviously, the output gap parameter is more affected than the inflation parameter. It is worth noting, however, that although the effect of the estimated output gap uncertainty is to move the efficient Taylor rule parameters in the direction of the values suggested by Taylor (1993), one needs either much larger output gap uncertainty or a strong interest rate smoothing objective to explain why actual estimated feedback parameters are so small. 


\section{Conclusions}

In this paper I have shown that, while uncertainty in the output gap does not affect optimal central bank behaviour in a linear-quadratic framework, it can have significant effects on restricted instrument rules such as the Taylor rule. In the extreme case, when measurement error in the output gap becomes large, the efficient Taylor rule parameter on the output gap could fall to zero.

Because the Taylor rule is suboptimal and its efficient feedback parameters vary with changes in the structure of the economy, no central bank would want to commit itself to following such a rule. Nevertheless, the finding that the Taylor rule is affected by measurement error in the output gap is of interest, because such a rule may play a useful role in monetary policy strategy in a number of respects. First, there is quite a lot of evidence that such simple rules are reasonably efficient at stabilising inflation and output in relatively closed economies such as the United States or the prospective euro zone. ${ }^{14}$ If this is the case, then a Taylor rule can be used by the central bank as an internal benchmark to gauge whether policy is on the right track. Second, while a fully statecontingent rule will always perform better, such rules are difficult to communicate. In contrast, a simple interest rate rule such as the Taylor rule is easy to understand and can be used by the central bank to explain its actions. By increasing policy transparency, a Taylor rule may reduce financial market volatility and help to establish the reputation of the central bank.

The methodology used in this paper can be used to extend research in a number of directions. First, in this paper I have focused on output gap measurement. Another source of additive measurement error in the Taylor rule lies in the estimation of the equilibrium real interest rate. In the estimated model of Section 2, I assumed that the equilibrium real interest rate is known and equal to the average real rate over the sample. In future research, it would be interesting to analyse the effect of this measurement error on optimal monetary policy behaviour (Rudebusch (1998)). In particular, it would be interesting to see whether such uncertainty can partially explain why central banks smooth interest rates.

Secondly, in this paper I have not analysed the effect of more general model parameter uncertainty. Preliminary results suggest that in our model this kind of uncertainty does not affect the optimal instrument rules very much (see also Estrella and Mishkin (1998)). An interesting topic for future research would be to see whether model parameter uncertainty affects the choice between using an inflation forecast and using actually observed inflation in simple instrument rules. Cecchetti (1995) has shown that it is generally very difficult to forecast inflation because of frequent breaks in the relationships between indicators and future inflation. As a result, such parameter uncertainty may

14 See Peersman and Smets (1998) for some evidence on the stabilisation properties of the Taylor rule in a model of the euro zone economy. 
introduce considerable measurement error into the inflation forecast. If this measurement error significantly reduces the optimal feedback parameter on the inflation forecast, then simple rules which respond to actually observed inflation may perform better. 


\section{References}

Ball, L. (1997): "Efficient rules for monetary policy", Reserve Bank of New Zealand Discussion Paper G97/3.

Brainard, W. (1967): "Uncertainty and the effectiveness of policy”, American Economic Review, Papers and Proceedings, Vol. 57, pp. 411-25.

Brayton, F., A. Levin, R. Tryon and J. Williams (1997): "The evolution of macro models at the Federal Reserve Board", Carnegie Rochester Conference Series on Public Policy, forthcoming.

Cecchetti, S. (1995): "Inflation indicators and inflation policy”, NBER Working paper 5161.

Cecchetti, S. (1997): "Central bank policy rules: conceptual issues and practical considerations", NBER Working paper 6306.

Chow, G. C. (1970): Analysis and control of dynamic economic systems, John Wiley and Sons, New York.

Clarida, R., J. Galí and M. Gertler (1997): “The science of monetary policy”, mimeo.

Clarida, R., J. Galí and M. Gertler (1998): "Monetary policy rules in practice: some international evidence", European Economic Review, Vol. 42, pp. 1033-68.

Clark, P. (1989): "Trend reversion in real output and unemployment", Journal of Econometrics, Vol. 40, pp. 15-32.

Estrella, A. and F. Mishkin (1997): "The role of NAIRU in monetary policy: implications of uncertainty and model selection", paper presented at the NBER Conference on Monetary Policy Rules held on 15-17th January 1998 in Islamorada, Florida.

Gerlach, S. and F. Smets (1997): "Output gaps and inflation: unobservable-component estimates for the G7 economies", unpublished manuscript, Bank for International Settlements.

Harvey, A. (1989): Forecasting, structural time series models and the Kalman filter, Cambridge University Press, Cambridge.

Henderson, D. and W. McKibbin (1993): "A comparison of some basic monetary policy regimes for open economies: implications of different degrees of instrument adjustment and wage persistence", Carnegie-Rochester Conference Series on Public Policy, Vol. 39, pp. 221-318.

Kuttner, K. (1994): "Estimating potential output as a latent variable", Journal of Business and Economic Statistics, Vol. 12, pp. 361-7.

Laubach, T. (1997): "Measuring the NAIRU: Evidence from seven economies", Research Working Paper 97-13, Federal Reserve Bank of Kansas City.

Levin, A. (1996): “A comparison of alternative monetary policy rules in the Federal Reserve Board's Multi-Country Model", in BIS (1996), The determination of long-term interest rates and exchange rates and the role of expectations, Basle, Switzerland.

Peersman, G. and F. Smets (1998): "The Taylor rule: a useful guide for monetary policy for the ECB?", paper presented at the Banca d'Italia workshop on "Monetary policy of the ESCB: strategic and implementation issues", 6-7th July 1998. 
Rudebusch, G. (1998): "Is the Fed too timid? Monetary policy in an uncertain world", manuscript, Federal Reserve Bank of San Francisco.

Rudebusch, G. and L. Svensson (1998): "Policy rules for inflation targeting", paper presented at the NBER Conference on Monetary Policy Rules held on 15-17th January 1998 in Islamorada, Florida.

Sack, B. (1998): "Does the Fed act gradually? A VAR analysis", Finance and Economics Discussion Series 1998-17, Federal Reserve Board, Washington, D.C.

Sargent, T. L. (1987): Dynamic macroeconomic theory, Harvard University Press, Cambridge MA.

Staiger, D., J. Stock and M. Watson (1996): "How precise are estimates of the natural rate of unemployment?", in: Romer, D. and C. Romer (eds.), Reducing inflation: motivation and strategy, University of Chicago Press.

Svensson, L. (1997): “Inflation targeting: some extensions”, NBER Working Paper 5962.

Taylor, J. (1993): "Discretion versus policy rules in practice", Carnegie-Rochester Conference Series on Public Policy, Vol. 39, pp. 195-214.

Wieland, V. (1997): "Monetary policy and uncertainty about the natural unemployment rate", mimeo, Board of Governors of the Federal Reserve System. 



\section{Recent BIS Working Papers}

No.

43

July 1997

44

July 1997

45

August 1997

46

September 1997

47

September 1997

48

September 1997

49

September 1997

50

November 1997

51

November 1997

52

January 1998

53

March 1998

54

June 1998

55

June 1998

56

June 1998

57

July 1998

58

November 1998

59

November 1998
Title

Exchange rate regimes and the expectations hypothesis of the term structure

Is there excess comovement of bond yields between countries?

A multi-country comparison of the linkages between inflation and exchange rate competitiveness

Global asset allocation in fixed income markets

Financial asset prices and monetary policy: theory and evidence

Some multi-country evidence on the effects of real exchange rates on output

Why does the yield curve predict economic activity?

Dissecting the evidence for Germany and the United States

The euro and the dollar

Forecast errors and financial developments

Inflation and disinflation in Iceland

Exchange rate regimes and inflation and output in SubSaharan countries

The coming transformation of continental European banking?

Spread overreaction in international bond markets

Commercial banks in the securities business: a review

One-step prediction of financial time series

The importance of bank seniority for relationship lending

Portfolio selection using fuzzy decision theory
Author

Stefan Gerlach and Frank Smets

Gregory D. Sutton

Steven B. Kamin

Srichander

Ramaswamy

Frank Smets

Steven B. Kamin and Marc Klau

Frank Smets and Kostas Tsatsaronis

Robert N. McCauley

Palle S. Andersen

Palle S. Andersen and Már Guðmundsson

Marc Klau

William R. White

Gregory D. Sutton

João A. C. Santos

Srichander Ramaswamy

Stanley D. Longhofer and João A. C. Santos

Srichander Ramaswamy 